\title{
Publisher Correction: Mycobacterium tuberculosis carrying a rifampicin drug resistance mutation reprograms macrophage metabolism through cell wall lipid changes
}

Nicole C. Howard, Nancy D. Marin, Mushtaq Ahmed, Bruce A. Rosa, John Martin, Monika Bambouskova, Alexey Sergushichev (D), Ekaterina Loginicheva, Natalia Kurepina, Javier Rangel-Moreno, Liang Chen, Barry N. Kreiswirth, Robyn S. Klein (D), Joan-Miquel Balada-Llasat, Jordi B. Torrelles, Gaya K. Amarasinghe, Makedonka Mitreva, Maxim N. Artyomov, Fong-Fu Hsu, Barun Mathema and Shabaana A. Khader (D)

Correction to: Nature Microbiology https://doi.org/10.1038/s41564-018-0245-0, published online 17 September 2018.

In the version of this Letter originally published, in Fig. $2 \mathrm{~d}$, in the third graph, the label for the $y$ axis was incorrect as 'TNF- $\alpha$ (pg ml $\left.{ }^{-1}\right)^{\text {'; }}$ it should have read 'IL-1 $\beta\left(\mathrm{pg} \mathrm{ml}^{-1}\right)$ '. This has now been corrected.

Published online: 16 October 2018

https://doi.org/10.1038/s41564-018-0281-9 